

\section{CLOCKWORK ANGELS OU UMA NOVA SAGA DO OTIMISMO}

JANAÍNA SANTOS*

RESUMo Este artigo faz uma análise comparativa entre uma obra contemporânea, Clockwork Angels, álbum conceitual da banda canadense Rush, e o livro Cândido, de Voltaire, filósfofo francês, cujo texto serve de inspiração para o álbum, como peça fundamental para a construção de personagens, ambientes e conceitos da história.

palavras-chave Clockwork Angels. Cândido. Otimismo.

\section{CLOCKWORK ANGELS OR ANOTHER SAGA OF OPTMISM}

ABSTRACT This article compares a contemporary work to a philosopher's famous text: Clockwork Angels, a conceptual album from Canadian band Rush, and Voltaire's Candid. The latter served as inspiration to the former, so that it is a fundamental part of the construction of characters, environments and concepts of the narrative.

KEYwOrds Clockwork Angels. Candid. Optimism.

* Mestranda, Unesp, São José do Rio Preto, SP. E-mail: j.asn@hotmail.com 


\section{Introdução}

\section{De como Leibniz irritou Voltaire até chegarmos aqui}

$\mathrm{Q}$ uem não gostaria de viver no melhor dos mundos possíveis? Com certeza, a maioria da humanidade gostaria. Houve até mesmo quem tentasse provar que isso já acontecia, e houve quem tentasse, consequentemente, argumentar que essa ideia era absurda. No primeiro caso, o polímata alemão Gottfried Wilhelm Leibniz desenvolveu uma linha de pensamento conhecida como Otimismo, que pode ser resumida na afirmação de que, sendo o universo criado por Deus, nele se torna possível conciliar o máximo de bem e o mínimo de mal, o que faz dele "o melhor dos mundos possíveis”. Há também na teoria de Leibniz uma tentativa de demonstrar que o mundo tem uma estabilidade por meio de uma uniformidade nos acontecimentos. Para Vagna, "no Discurso de Metafísica, Leibniz diz não ser possível imaginar no mundo eventos que não evidenciam alguma uniformidade, por mais complexos que eles possam ser." (VAGNA, 2006, p. 50).

Entretanto, como já mencionado, houve quem discordasse desse posicionamento e o combatesse: para isso nasceu a obra Cândido ou O Otimismo, de Voltaire, I759, uma resposta satírica a certas linhas filosóficas da época, como as de Rousseau e de Leibniz. O texto trata de um jovem de nome Cândido que havia sido criado em um lindo castelo na Vestfália, com uma vida abastada e tranquila, sendo ensinado pelo mestre Pangloss (discípulo declarado de Leibniz) que, em todo e qualquer aspecto, a melhor vida possível seria estar no melhor mundo possível, ou seja, no mundo em que viviam. Entretanto, por uma “queda” romântica pela senhorita Cunegundes, filha do barão dono do castelo, o jovem é expulso do seu lar e passa a enfrentar uma série de desventuras que vão pondo em xeque todo o seu aprendizado sobre o Otimismo.

Esse conto filosófico influenciou vários artistas ao longo do tempo e, entre eles, o compositor e baterista Neil Peart, da banda canadense Rush: o letrista do álbum 
Clockwork Angels admite, no posfácio do livro adaptado do disco, que buscou, no conto de Voltaire, a base para o arco narrativo da história.

Assim, este texto aborda aspectos em que a história de Voltaire e, consequentemente, a teoria do otimismo - conforme apresentada em Cândido -, aparecem tanto na construção do arco da narrativa de Clockwork Angels como na construção dos personagens e na mentalidade social e política ambientada naquele mundo, tornando-se, assim, "uma nova saga do otimismo".

\section{De como a banda nasceu até o surgimento de Clockwork Angels}

A banda Rush foi formada em I968 em Toronto, Canadá, por Alex Lifeson (guitarra), Jeff Jones (baixo), substituído em seguida por Geddy Lee (baixo, teclado e vocal), e John Rutsey (baterista). John Rutsey deixa a banda pouco depois do lançamento do primeiro álbum, em I974, e é substituído por Neil Peart. Essa formação permaneceu até 2015, ano em que a banda anunciou um afastamento dos palcos.

No início da carreira, ao tocar pelas primeiras vezes nas rádios, o Rush foi comparado, inclusive por causa do timbre de seu vocalista, com o grupo inglês Led Zeppelin. Entretanto, a banda acabou por desenvolver uma sonoridade peculiar, com composições bastante elaboradas para serem tocadas por apenas três pessoas: o que havia começado como uma tendência hard rock no primeiro álbum se modificou e mostrou características de rock progressivo em discos seguintes, ainda na década de 70, por influência de bandas como Yes, Van der Graaf Generator e King Crimson. Na década seguinte, as músicas se tornaram menores e algumas foram compostas sob a influência do ska, reggae, funk e New Wave, o que ocasionou o amplo uso de teclados nas composições dessa época ${ }^{\mathrm{I}}$. Contudo, mesmo depois de quarenta anos de carreira, dificilmente a 1 https://www.rush.com/

banda pode ser classificada em um subgênero específico do rock, sendo um símbolo band/ de sonoridade peculiar. Rush sempre soa como Rush.

O ingresso do novo baterista acarretou uma mudança significativa nas composições: Peart se torna o letrista, e sua qualidade de leitor voraz terá papel fundamental na carreira da banda, pois, motivado por suas leituras, compõe várias canções, utilizando- 
2 https://rushvault. com/2013/07/11/geddyrush-never-stopped-doingconcept-albums/ se de fontes literárias - “Tom Sawyer” (As Aventuras de Tom Sawyer, Mark Twain), "Xanadu" (inspirada no poema Kubla Khan, de Samuel Taylor Coleridge), "Rivendell" e “The Necromancer” (O Senhor dos Anéis, J. J. R. Tolkien) e o álbum Clockwork Angels, com seu arco narrativo inspirado em Cândido, de Voltaire.

A banda também aderiu, ao longo da carreira, à ideia de compor álbuns conceituais. Em I975, o álbum Caress of Steel traz a música “The Fountain of Lamneth”, com quase 20 minutos de duração e dividida em seis partes que narram a busca pela fonte de Lamneth. Em I976, é lançado o álbum 2112, baseado na leitura de Peart, do livro Anthem, de Ayn Rand. Apesar de apenas um lado do álbum ser dedicado a essa música, ele é considerado, em linhas gerais, como conceitual. Ao longo dos anos, de acordo com seus integrantes, a banda continuou a lançar outros discos que são considerados conceituais temáticos, porém não necessariamente divulgados como tais ${ }^{2}$, a exemplo de Hemispheres, Grace under Pressure, Power Windows, Roll the Bones, Counterparts, para citar alguns. E finalmente, depois de explorar essas possibilidades em vários de seus trabalhos, a banda lança, em 20I2, um álbum inteiro com uma narrativa: Clockwork Angels.

A história no álbum é narrada quase totalmente em primeira pessoa (mas não por um único narrador) em ordem cronológica. Cada música tem a função de apresentar um acontecimento marcante na vida do narrador. Também, para que haja uma contextualização e uma imersão mais rápida e pontual na história, o encarte traz, antes de cada letra, um texto introdutório que cria o contexto (físico, emocional ou conceitual) em que se situará a ação retratada ou a reflexão contida nela.

Com base na história que o álbum propõe, foi lançado também, em 20I2, um romance escrito pelo autor de ficção científica Kevin J. Anderson, em parceria com o baterista/letrista Neil Peart, e com ilustrações de Hugh Syme. Com a novelização das letras, as aventuras em que o herói participa são incrementadas de detalhes, e o tema “Ordem x Caos”, que já podia ser percebido nas canções, torna-se mais elaborado, bem como o tema “Livre Arbítrio x Destino”. A adaptação, no entanto, não se deteve ao romance: ao longo de 20I5, uma novela gráfica foi lançada em seis volumes, sendo parceria entre o autor do livro e o artista Nick Robles.

Assim, com Clockwork Angels, a banda une duas práticas comuns em sua carreira: a influência literária e os álbuns conceituais. 


\section{Do resumo de Clockwork Angels}

O álbum, o romance e a novela gráfica apresentam ao leitor/ouvinte a mesma sequência de eventos: inicia-se pela apresentação do personagem principal já idoso, que começa a narrativa com suas lembranças, chegando até a retomada de sua reflexão sobre a vida no fim da história. Por isso, será feito aqui um resumo utilizando-se as letras das canções, visto que são a obra-base para as adaptações, e estas, por sua vez, acompanham a sequência dos acontecimentos que se encontram no álbum.

A primeira música, "Caravan"3, é iniciada com leves sons de sinos ao longe, que vão ficando mais altos, como se anunciassem a chegada de uma caravana ${ }^{4}$.

O texto introdutório e a letra da música apresentam o personagem principal e uma pequena reflexão a respeito de sua vida. Ele explica que seu mundo é governado pelo Relojoeiro (Watchmaker), um líder que programa todas as atividades das vidas dos habitantes e propaga a ideia de que "tudo está para o melhor", assim como é ensinado a Cândido por meio de seu mentor, Pangloss, no livro de Voltaire. Fazendo um balanço positivo (otimista) de sua vida, o personagem, que, com a novelização do álbum, ganha o nome de Owen Hardy, conta que caravanas de steamliners (zepelins movidos a fogo frio) passavam perto da fazenda onde morava e, em uma dessas passagens, ele embarca em um dos veículos que se dirigia para Crown City, capital de Albion. Nesse momento, ele deixa sua vida pacata e pré-determinada e parte para o início do que se torna uma aventura pelo mundo.

$\mathrm{Na}$ música seguinte, "BU $2 \mathrm{~B}$ ", sigla para "Brought up to believe" (Criado para acreditar), o personagem faz uma reflexão a respeito das crenças nas quais foi criado e se mostra insatisfeito com elas, afinal ele havia sido ensinado a acreditar que cada indivíduo merecia o que lhe acontecia e que era preciso aceitar o destino individual como inevitável, pois o universo sempre teria o melhor plano possível para cada um.
3 https://www.youtube. com/watch?v=6yBFQıuraık

4 A ilustração que faz fundo à letra no encarte retrata os veículos, steamliners, que formam a caravana, além de um personagem que pode representar 0 protagonista da história no alto de uma plataforma. Essa e outras ilustrações que compõem o álbum e o livro podem ser vistas neste link do site do ilustrador Hugh Syme: http://www. hughsyme.com/\#35

5 https://www.youtube. com/watch?v=8O_il4gGpao
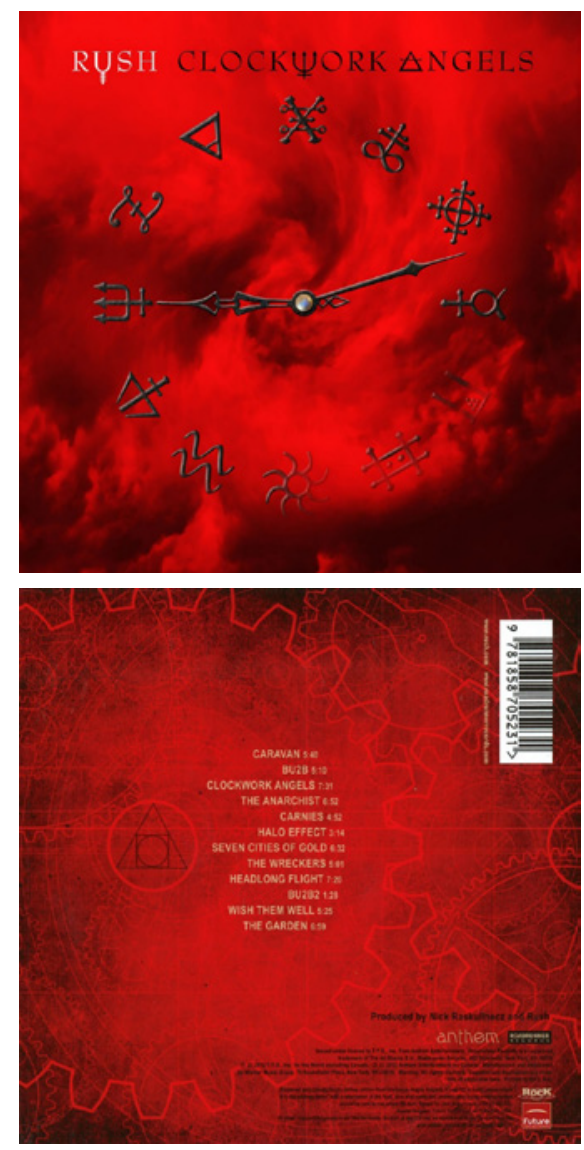

FIGURAS 1 e 2 - Capa e contracapa do encarte do álbum Clockwork Angels, 2012. 
6 https://www. youtube.com/ watch?v=7P8EOOvalSg
7 A imagem pode ser vista no site do ilustrador, no link citado acima, sendo a segunda na sequência

(The pedlar).

8 https://www.

youtube.com/ watch? $v=\mathrm{GHH}$ vfSdTPbs

9 https://www. youtube.com/ watch? $v=B m L E s L F 7 A T I$

10 https://www. youtube.com/ watch? $v=5 g s \mathrm{Oxmyp} 5 \mathrm{YI}$

11 https://www.youtube. com/watch?v=coDiftbPJ8Q

12 https://www.youtube. com/watch?v=InYIKgnLrdM

https://www. youtube.com/ watch?v=xKFgtZQpfYU
Clockwork Angels ${ }^{6}$ descreve o impacto que a crença nas deusas-anjo tem sobre o protagonista e sobre o povo em geral, pois, mesmo depois de se decepcionar com algumas crenças, ele ainda se assombra com a grandiosidade da "maquinária espiritual".

As duas letras seguintes são casos à parte por diferentes razões: “i - The Pedlar I” não é uma música, mas aparece apenas no encarte como uma pequena descrição de um personagem que aparece em uma ilustração ${ }^{7}$ - um caixeiro viajante que anda pelo mundo perguntando aos prospectivos compradores: “O que lhe falta?”. Essa fala, mesmo que apenas escrita, faz a ligação com o texto introdutório da música seguinte "The Anarchist" - , em que esse personagem se torna, excepcionalmente, o narrador e diz ouvir a pergunta do caixeiro, respondendo que o que lhe falta é vingança.

Essa vingança é mostrada na música seguinte, “Carnies” 9 . O protagonista volta a ser o narrador e está trabalhando em um circo na capital quando vê um homem lidando com fios, barris de madeira e um detonador - era o Anarquista. Quando o herói grita para alertar a multidão, o homem joga o detonador para suas mãos e desaparece. O narrador diz, então, que precisou fugir da multidão enfurecida que lhe atribuía o ataque.

Na sequência, "Halo Effect" circo, à qual havia se juntado para trabalhar, e sua decepção com esse sentimento.

"Seven Cities of Gold" II fala da busca do personagem pela lenda das cidades de ouro. Ele atravessa terras geladas e inóspitas depois de trabalhar por um tempo na cidade portuária de Poseidon. A letra não revela abertamente se ele encontra o que procura. Entretanto, a música seguinte, “The Wreckers” ${ }^{\text {I2 }}$, diz que ele escapa por pouco de uma morte congelante naqueles desertos e que volta a Poseidon a fim de, a partir dali, ir para sua terra natal. Para isso, ele embarca em um navio que é pego por uma terrível tempestade, no meio da qual uma luz no horizonte parece ser a única salvação. Indo em direção a ela, o navio é pego em uma armadilha, a carga é saqueada, e a tripulação é abandonada pelos saqueadores para morrer no naufrágio. O narrador é o único sobrevivente. Essa é a última aventura contada no álbum, pois as canções seguintes são marcadas por reflexões a respeito da vida do protagonista.

“Headlong Flight” ז3 é uma consideração a respeito das aventuras pelas quais o herói passou. Mesmo que elas não parecessem tão "grandes", nos momentos em que as viveu, ele afirma que as viveria de novo.

Novamente o caixeiro viajante aparece apenas no encarte com "ii - The Pedlar 2" para perguntar mais uma vez: “O que lhe falta? ”. Dessa vez, o questionamento é 
"respondido" pelo protagonista, na curta, porém muito significativa, "BU2B2"I4. Aqui ele reflete sobre tudo o que ele perdeu ao longo de sua jornada, e o que se destaca é a perda do otimismo desenfreado. Apesar disso, ele, ironicamente, ainda acredita no amor, assim como foi criado para acreditar.

"Wish them well" Is observa que a raiva e o rancor são sentimentos prejudiciais e não são dignos de ser nutridos por causa de pessoas que fazem o mal. O que deve ser feito é se afastar e desejar o melhor a elas.

“The Garden”ㄷ́ é o “agora” na narração: o protagonista mostra, citando Cândido (agora devemos cultivar nosso jardim), que a verdadeira busca de toda sua vida foi para colher respeito e amor, que é, sim, a verdadeira medida da vida.

Com a consideração das letras, fica evidente que o personagem não se sente completo naquele sistema em que tudo é planejado e, por isso, sai em busca de uma vida diferente.
14 https://www. youtube.com/ watch?v=8mvKHG1YS34

15 https://www youtube.com/ watch?v=1ns9BvYz8WE

16 https://www.youtube. $\mathrm{com} /$ watch? $\mathrm{v}=\mathrm{SAxtFSpHxts}$

\section{De como Cândido coopera para a existência de Clockwork Angels}

Neil Peart tem buscado, ao longo de sua carreira, conforme exemplificado anteriormente, inspiração em várias obras literárias para a elaboração de suas letras. No posfácio do romance Clockwork Angels (Os Anjos do Tempo, em português), ele comenta a respeito da escolha de Cândido como modelo para a história:

Cândido, de Voltaire (1759), foi um modelo inicial para o arco narrativo: uma sátira filosófica sobre um jovem otimista e ingênuo cuja criação (Eu fui levado a crer) não serviu para prepará-lo para as angustiantes aventuras que lhe causaram desilusão, tristeza e desespero. Finalmente, Cândido encontra a paz e a sabedoria em uma fazenda próxima a Constantinopla, trabalhando em seu jardim (ANDERSON, 20I5, p. 289).

Assim, Cândido é o texto do qual Clockwork Angels "brota”: Peart traça linhas gerais de aventuras e crenças inspiradas em Cândido, porém contando uma história num "estilo" completamente diferente do de Voltaire: enquanto o filósofo questiona a máxima “tudo está bem”, de uma maneira ácida, satírica, fazendo o protagonista do seu conto sofrer grandes desgraças e ouvir narrativas de infortúnios imensos de outros personagens, Peart constrói um mundo que não aparenta ser ruim. 
Cândido é ensinado por Pangloss (discípulo declarado de Leibniz) a acreditar que o mundo em que vivia era o melhor possível, mesmo se algo saísse errado. Tudo tinha seu motivo:

Pangloss ensinava metafísico - teólogo - cosmolonigologia. Provava admiravelmente que não há efeito sem causa e que, neste que é o melhor possível dos mundos, o castelo do senhor barão era o mais belo possível dos castelos, e a senhora, a melhor das baronesas possíveis (VOLTAIRE, I759, p. I8).

Cândido ouvia com toda a atenção e acreditava inocentemente; pois achava a senhorita Cunegundes extremamente formosa, embora jamais se atrevesse a lho dizer. Concluía que, depois da ventura de ter nascido barão de Thunder-ten-tronckh, o segundo grau de felicidade consistia em ser mademoiselle Cunegundes; o terceiro, em vê-la todos os dias; e o quarto, em ouvir mestre Pangloss, o maior filósofo da província e, por conseguinte, de toda a terra (VOLTAIRE, I759, p. I9).

No decorrer da história, entretanto, Cândido depara com situações que o fazem questionar a veracidade das palavras de seu querido instrutor a ponto de rejeitar sua crença no Otimismo:

- Sim, é o costume - disse o negro. - Por todo vestuário, dão-nos umas calças duas vezes por ano. Quando trabalhamos nas usinas de açúcar e o rebolo nos apanha o dedo, cortam-nos a mão; quando tentamos fugir, cortam-nos a perna: incorri em ambos os casos. É por esse preço que os senhores comem açúcar na Europa. No entanto, quando me vendeu por dois escudos patagônicos na Costa da Guiné, minha mãe me dizia: "Bendiz a nossos fetiches, meu querido filho, adora-os sempre, eles farão com que vivas feliz; tens a honra de ser escravo dos nossos senhores brancos, e com isso fazes a fortuna de teu pai e de tua mãe". Ai! Se fiz a fortuna deles é coisa que eu não sei, mas eles não fizeram a minha. Os cachorros, macacos e papagaios são mil vezes menos infelizes que nós. Todos os domingos, os fetiches holandeses que me converteram me dizem que nós, brancos e negros, somos todos filhos de Adão. Não sou genealogista, mas se esses pregadores dizem a verdade, somos todos primosirmãos. Ora, hão de confessar-me que é impossível tratar os parentes de modo mais horrível. - Ó Pangloss! - exclamou Cândido. - Não tinhas imaginado esta abominação; não há remédio, acabo renegando o teu otimismo.

- Que é otimismo? - indagou Cacambo.

- É a mania de sustentar que tudo está bem quando tudo está mal - suspirou Cândido.

E derramava lágrimas ao contemplar o negro, e, assim chorando, entrou em Surinam (VOLTAIRE, I759, p. 37). 
O personagem do álbum é criado em uma sociedade que acredita viver no melhor dos mundos possíveis. Assim, a crença satirizada por Voltaire é utilizada por Peart para construir a mentalidade por meio da qual o Relojoeiro governa: entende-se, ao longo da história, que, em um passado não muito distante, havia anarquia e dificuldades em -Albion. De alguma maneira, então, aquele líder tomou o poder e fez o povo ter a organização necessária para que se instaurasse paz, harmonia e uma boa medida de predição nos acontecimentos, ou seja, a população acreditava que vivia no melhor dos mundos possíveis, não havendo por que se preocupar com o amanhã; afinal "tudo estaria para o melhor". Entretanto, o personagem do álbum, assim como Cândido, também se incomodava com o mundo em que vivia e com as crenças que lhe impuseram a vida toda. A letra da música abaixo (juntamente com o trecho introdutório) é um exemplo dessa reflexão que lhe gera incômodo:

\section{Criado Para Acreditar (BU2B)}

SEMPRE FOMOS ENSINADOS que vivemos no "melhor dos mundos possiveis". O Relojoeiro governava

de Crown City por meio dos Reguladores; os sacerdotes-alquimistas nos deram o fogo frio de poder e luz, e tudo era bem organizado. Nós aceitávamos nossos vários destinos individuais como inevitáveis, pois também havíamos sido ensinados, "Seja o que nos aconteça deve ser o que merecemos, pois não aconteceria a nós se não merecêssemos". Nada disso parecia certo para mim...

Eu fui criado para acreditar Que o universo tem um plano Somos apenas seres humanos Não é nosso dever entender O universo tem um plano Tudo é para o melhor Alguns serão recompensados E o diabo leva o resto Tudo é para o melhor Acredite no que nos foi dito 
Comprando o que nos é vendido

Acredite no que nos foi dito

Até nosso último suspiro

Enquanto nosso amoroso Relojoeiro

Ama todos nós até a morte

Em um mundo de discussões

Sempre fui ensinado a confiar Em um mundo onde todos devem falhar

A justiça do céu irá prevalecer

A alegria e a dor que recebemos Cada qual vem com seu próprio custo

O preço que estamos ganhando

É o mesmo que perdemos

Até nosso último suspiro

A alegria e a dor que recebemos

Deve ser o que merecemos

17 A letra no idioma original

Eu fui criado para acreditar ${ }^{17}$ encontra-se no Anexo.

É possível, portanto, enxergar essa sociedade instaurada e governada pelo Relojoeiro como a concretização da utopia otimista de uma "harmonia preestabelecida" pregada por Pangloss:

- Pois bem! Meu caro Pangloss - disse Cândido - enquanto eras enforcado, dissecado, espancado e remavas nas galeras, sempre achavas que tudo ia o melhor possível?

- Mantenho a minha primitiva opinião - respondeu Pangloss -, pois, afinal, sou filósofo: não me convém desdizer-me, visto que Leibniz não pode incorrer em erro, e a harmonia preestabelecida é a mais bela coisa do mundo, bem como o todo e a matéria sutil (VOLTAIRE, p. I77).

Essa mentalidade de "harmonia preestabelecida" é afirmada no álbum, e, assim como acontece com Cândido, o herói acredita nisso durante certo tempo.

Entretanto, em Clockwork Angels, não há uma posição definitiva por parte do protagonista a favor do Otimismo (representado pelo Relojoeiro e seu mundo) ou contra ele 
(o Anarquista apresenta-se como o antagonista daquele governante e daquele sistema, porém seu papel na trama é mais significativo na novelização do álbum). Há momentos de aceitação das crenças, mas há momentos de questionamento, assim como há em Cândido - o garoto que embarca em um steamliner, procurando fazer o bem e saciar sua curiosidade a respeito do mundo, decepciona-se ao ser levado a refletir sobre a sua realidade, mas, por outro lado, não desiste de acreditar que dar de si ainda é o melhor a fazer, pois havia sido criado para acreditar. A letra da música a seguir relata a desilusão nas crenças ensinadas e a escolha de perseverar, assim como Cândido, apesar da decepção:

\section{Criado Para Acreditar 2 (BU2B2)}

AQUELAS PALAVRAS FATAIS. "O que lhe falta?" desencadeia um monólogo interior sobre tudo o que perdi. Nunca mais otimismo ilimitado, nunca mais fé em poderes maiores, dor demais, sofrimento demais e desilusão demais. Apesar de tudo isso, percebo a ironia de que, apesar de agora eu somente acreditar na troca de amor, até a pequena fé segue o reflexo da infância em que "fui criado para acreditar".

Eu fui criado para acreditar

A crença me falhou agora

O brilho intenso de otimismo Abandonou-me de alguma forma

A crença me falhou agora

A vida vai de mal a pior Nenhuma filosofia me consola

Em um universo mecânico

A vida vai de mal a pior

Eu ainda escolho viver

Procurando uma medida de amor e riso

E outra medida para oferecer

Eu continuo escolhendo viver

E oferecer, mesmo enquanto eu sofrer

Embora o equilíbrio se incline contra mim

Eu fui criado para acreditar ${ }^{18}$

$18 \mathrm{~A}$ letra no idioma original encontra-se no Anexo. 
Vemos, assim, que a mentalidade predominante na sociedade na qual a história de Clockwork Angels se passa, bem como a viagem que faz o garoto perder sua inocência, são aspectos, entre outros, que aproximam ambas as obras. O fim do álbum contém até mesmo uma citação direta do texto de Voltaire, além de ser construído em harmonia com o final do conto.

\section{De como cuidar de seu jardim}

Novamente no posfácio do livro, Peart comenta que utilizou o texto de Voltaire para construir mais uma parte de sua narrativa:

Na cena final de Cândido, o personagem que dá nome ao livro expressa sua impaciência com a filosofia e revela a sabedoria pragmática que acumulou. "Às vezes Pangloss dizia a Cândido: ‘Todos os acontecimentos estão encadeados no melhor dos mundos possíveis; pois, afinal, se não tivesses sido expulso de um belo castelo com grandes pontapés no traseiro, por causa do amor da senhorita Cunegundes, se não fosses apanhado pela Inquisição, se não tivesses percorrido a América a pé, se não tivesses dado uma boa espadada no barão, se não tivesses perdido todos os teus carneiros do bom país de Eldorado, não estarias comendo aqui cidras em calda e pistaches'. 'Isto está bem dito, respondeu Cândido, mas é preciso cultivar nosso jardim.'”(ANDERSON, 20I5, p. 29I).

Por fim, Cândido se estabelece em Constantinopla e finalmente, em certa medida, desfruta de paz por trabalhar e cultivar seu jardim enquanto Pangloss "prova" que tudo que aconteceu com ele teve um propósito.

O texto introdutório da última música, “The Garden”, faz a citação da passagem acima para contar que o protagonista de Clockwork Angels seguiu um caminho semelhante ao escolher também cultivar seu próprio jardim:

\section{O Jardim}

HÁ MUITO TEMPO ATRÁS LI UMA HISTÓRIA DE OUTRA LINHA DO TEMPO sobre um personagem chamado Cândido. Ele também sobreviveu a uma série angustiante de desventuras e tragédias, então se estabeleceu numa fazenda em Constantinopla. Ouvindo um discurso filosófico, Cândido respondeu: "Isso tudo é muito bom, mas agora devemos cuidar do nosso jardim". Agora eu chego nesse ponto da minha própria história. Há um jardim metafórico nos atos e atitudes da vida de uma pessoa, e os tesouros desse jardim são o amor e respeito. Vim a perceber que a colheita do amor e do respeito - dos outros e para mim mesmo - tem sido a busca real da minha vida. 
"Agora devemos cuidar do nosso jardim".

Neste dos muitos mundos possíveis,

Tudo para o melhor ou algum teste bizarro?

É o que é - seja o que for

O tempo ainda é uma piada infinita

A flecha voa quando você sonha, As horas tiquetaqueiam - as células tiquetaqueiam

O Relojoeiro mantém seus planos

As horas tiquetaqueiam - elas tiquetaqueiam

A medida de uma vida é a medida do amor e respeito

Tão difícil de ganhar, tão facilmente queimada

Na plenitude dos tempos

Um jardim para nutrir e proteger

No nascer e no pôr do sol

Até as estrelas irem girando - girando em torno da noite

É o que é - e para sempre

Cada momento uma lembrança em pleno voo

A flecha voa enquanto você respira,

As horas tiquetaqueiam - as células tiquetaqueiam

O Relojoeiro tem tempo de sobra

As horas tiquetaqueiam - elas tiquetaqueiam

O tesouro da vida é uma medida de amor e respeito

A maneira como você vive, os presentes que dá

Na plenitude dos tempos

É o único retorno que você espera

O futuro desaparece na memória

Em apenas um instante

Para sempre habita naquele momento

A esperança é o que permanece para ser vista ${ }^{19}$

19 A letra no idioma original encontra-se no Anexo. 
Assim, ambos os heróis aqui estudados acabam por constatar, por meio de suas viagens e experiências, que nem tudo estava para o melhor em seu mundo e que o otimismo desenfreado não lhes trouxera satisfação plena (nem mesmo no mundo do Relojoeiro!). Mesmo assim, ainda era necessário continuar a viver, e ambos fizeram suas escolhas: sem desejarem mudar o mundo, foram cuidar de seus jardins.

\section{Das considerações finais}

É muito interessante observar o fato de uma banda de rock da atualidade recorrer à obra Cândido e notar que o texto de Voltaire não está apenas nas entrelinhas para leitores que já o conhecem e que certamente perceberão sua influência, já que a essência do conto do filósofo francês está exposta no álbum, o que pode motivar algumas pessoas a recorrer à obra inspiradora e, assim, ter uma outra experiência de leitura/audição de Clockwork Angels.

Também é necessário relembrar que, enquanto Voltaire constrói uma crítica feroz a uma crença utópica de otimismo desenfreado, as letras e as adaptações não são satíricas. Mesmo assim, elas trazem consigo a reflexão a respeito de ideias antagônicas levadas ao extremo e o caminho que toma um homem comum. O personagem opta pelo meio termo, quase que com uma posição neutra em relação ao seu mundo - ele não está mais na fazenda de seu pai e nem segue o cronograma que o Relojoeiro traçou para sua vida, mas também não escolhe se tornar rebelde, como fez o Anarquista. Assim como o personagem de Voltaire, ele se encaixa no sistema social e político no qual vive e passa a cultivar seu próprio jardim, ou seja, ambos os protagonistas decidem não optar pelos lados que lhes são apresentados, para viverem cegamente suas promessas, mas escolhem viver suas próprias vidas, na medida do possível, à maneira que lhes parece mais apropriada.

Por fim, poderíamos até mesmo dizer, lembrando o herói da Vestfália, que "todos os acontecimentos estão devidamente encadeados no melhor dos mundos possíveis". Afinal, se não fosse o Otimismo de Leibniz incomodar Voltaire a ponto de esse filósofo se dar o trabalho de escrever Cândido, e se Neil Peart não fosse o letrista do Rush, e se essa banda não tivesse o hábito de compor álbuns conceituais, não estaríamos aqui concluindo que seria impossível pensar na elaboração de Clockwork Angels sem a existência de Cândido. Assim, "tudo estando muito bem dito", até certo ponto, neste caso, “tudo está o melhor possível”. 


\section{Referências}

ANDERSON, K. J. Clockwork Angels: os anjos do tempo. Tradução. Bruno Mattos. Caxias do Sul: Belas Letras, 2015.

HEGARTY, P.; HALLIWELL, M. The Concept Album. In: Beyond and Before: Progressive Rock since the 1960s. Bloomsbury Publishing, USA, 20 II.

LEIBNIZ, G. Discurso de metafísica e outros textos. São Paulo: Martins Fontes, 2004.

RUSH. Clockwork Angels. Nashville/Toronto: Roadrunner Records, 20I2. I disco sonoro. VAGNA, R. Leibniz e sua concepção do melhor dos mundos. In: Revista de Iniciação Científica da FFC, v. 6, n. I/2/3, p. 46-53, 2006.

VOLTAIRE, Cândido ou O Otimismo. I759. Disponível em: <http://www.ebooksbrasil. org/eLibris/candido.html>. Acesso em: ı2 nov. 2016.

\section{Anexo}

\section{$B U 2 B$}

WE WERE ALWAYS TAUGHT that we lived in "the Best of all possible worlds." The Watchmaker ruled from Crown City through the Regulators; the alchemist-priests gave us coldfire for power and light, and everything was well ordered. We accepted our various individual fates as inevitable, for we had also been taught, "Whatever happens to us must be what we deserve, for it could not happen to us if we did not deserve it."

None of it seemed right to me...

I was brought up to believe

The universe has a plan

We are only human

It's not ours to understand 
The universe has a plan

All is for the best

Some will be rewarded

And the devil, take the rest

All is for the best

Believe in what we're told

Blind men in the market

Buying what we're sold

Believe in what we're told

Until our final breath

While our loving Watchmaker

Loves us all to death

In a world of cut and thrust

I was always taught to trust

In a world where all must fail

Heaven's justice will prevail

The joy and pain that we receive

Each comes with its own cost

The price of what we're winning

Is the same as what we've lost

Until our final breath

The joy and pain that we receive

Must be what we deserve

I was brought up to believe 


\section{BU2B2}

THOSE FATEFUL WORDS, “What do you lack?” spark an inner monologue about all that I have lost. No more boundless optimism, no more faith in greater powers, too much pain, too much grief, and too much disillusion. Despite all that, I realize the great irony that although I now believe only in the exchange of love, even that little faith follows the childhood reflex that "I was brought up to believe."

I was brought up to believe

Belief has failed me now

The bright glow of optimism

Abandoned me somehow

Oh, belief has failed me now

Life goes from bad to worse

No philosophy consoles me

In a clockwork universe

Oh, life goes from bad to worse

I still choose to live

Find a measure of love and laughter

And another measure to give

Oh, I still choose to live and give

Even while I grieve

Though the balance tilts against me

I was brought up to believe 


\section{THE GARDEN}

LONG AGO I READ A STORY FROM ANOTHER TIMELINE about a character named Candide. He also survived a harrowing series of misadventures and tragedies, then settled on a farm near Constantinople. Listening to a philosophical rant, Candide replied,

"That is all very well, but now we must tend our garden."

I have now arrived at that point in my own story. There is a metaphorical garden in the acts and attitudes of a person's life, and the treasures of that garden are love and respect. I have come to realize that the gathering of love and respect - from others and for myself - has been the real quest of my life.

"Now we must tend our garden."

In this one of many possible worlds,

All for the best, or some bizarre test?

It is what it is - and whatever

Time is still the infinite jest

The arrow flies when you dream, The hours tick away - the cells tick away The Watchmaker keeps to his schemes

The hours tick away - they tick away

The measure of a life is a measure of love and respect

So hard to earn, so easily burned

In the fullness of time

A garden to nurture and protect

In the rise and the set of the sun

'Til the stars go spinning - spinning 'round the night

It is what it is - and forever

Each moment a memory in flight 
The arrow flies while you breathe, The hours tick away - the cells tick away The Watchmaker has time up his sleeve

The hours tick away - they tick away

The treasure of a life is a measure of love and respect

The way you live, the gifts that you give

In the fullness of time

It's the only return that you expect

The future disappears into memory

With only a moment between

Forever dwells in that moment

Hope is what remains to be seen 